\title{
Aspects of cognitive performance relating to Theory of Mind (ToM) among people diagnosed with Post-Traumatic Stress Disorder (PTSD) [Retraction]
}

Altunbaş FD, Onen Unsalver B, Yasar AB. Neuropsychiatr

Dis Treat. 2019;15:2015-2025.

At the request of the authors, the Editor-in-Chief and Publisher of Neuropsychiatric Disease and Treatment wish to retract the published article.

Concerns were raised to the Editor regarding the data and results reported in the article. The Reading the Mind in the Eyes Test (RMET) mean score reported in healthy controls and the PTSD group was 31 and 24, respectively. It was noted that while a mean score of 31 was exceptionally high for the 36-item version of the RMET, it was unbelievably high for the 32-item Turkish version the authors reportedly used for their study.

The authors also reported a similarly large effect for the Hinting task with means of 16.5 and 25.8 for the patient and healthy control group, respectively. Given the Hinting task has a score range of 0 (min) to 20 (max), a mean score of 25.8 for the healthy control group was not possible.

Following an internal investigation, the authors found some RMET values were higher than expected. Four subjects scores were recorded as 33 and 34, one subject had a score of 35 and two subjects had scores of 36 . Since the authors used the 32-item Turkish version of the RMET, scores above 32 were not possible. Searching through the hard copy reports it was found the values for these subjects had been mistakenly entered into the SPSS file and they should have been $23,24,25$ and 26 .

The Hinting Task database also showed two Hinting task values of 202 and 29 had been wrongly entered. The wrong entry had been noticed by a statistician and the mean score had been corrected accordingly, however, the wrong table was included in the submitted manuscript.

The Editor determined the results and findings of the article were no longer valid and advised a retraction as the only course of action, to which the authors also agreed.

The authors wish to apologise for this error.

Our decision-making was informed by our policy on publishing ethics and integrity and the COPE guidelines on retraction.

The retracted article will remain online to maintain the scholarly record, but it will be digitally watermarked on each page as "Retracted".
Neuropsychiatric Disease and Treatment is an international, peerreviewed journal of clinical therapeutics and pharmacology focusing on concise rapid reporting of clinical or pre-clinical studies on a range of neuropsychiatric and neurological disorders. This journal is indexed on PubMed Central, the 'PsycINFO' database and CAS, and is the official journal of The International Neuropsychiatric Association (INA). The manuscript management system is completely online and includes a very quick and fair peer-review system, which is all easy to use. Visit http://www.dovepress.com/testimonials.php to read real quotes from published authors. 